University of Massachusetts Amherst

ScholarWorks@UMass Amherst

Chemistry Department Faculty Publication Series

Chemistry

2003

\title{
Comparison of supported liquid membranes and solid-phase extraction for quantitative removal of lead from aqueous solutions
}

ER Yourd

JF Tyson

Follow this and additional works at: https://scholarworks.umass.edu/chem_faculty_pubs

\section{Recommended Citation}

Yourd, ER and Tyson, JF, "Comparison of supported liquid membranes and solid-phase extraction for quantitative removal of lead from aqueous solutions" (2003). CANADIAN JOURNAL OF CHEMISTRY-REVUE CANADIENNE DE CHIMIE. 1029.

Retrieved from https://scholarworks.umass.edu/chem_faculty_pubs/1029 


\title{
Comparison of supported liquid membranes and solid-phase extraction for quantitative removal of lead from aqueous solutions
}

\author{
Emily R. Yourd and J ulian F. Tyson
}

\begin{abstract}
The selective transport of a target metal ion across a membrane from a donor to an acceptor solution is an attractive concept for preconcentration or separation in a flow injection (FI) system. However, we found that the transport of lead across a supported liquid membrane consisting of dicyclohexano-18-crown-6 in decanol embedded in Celgard 2400 was too slow to be practical for an FI atomic spectrometry system. On the other hand, the same chemistry in an on-line, solid-phase reactor (a mini-column containing $\mathrm{Pb}-\mathrm{Spec}$ resin) gave a satisfactory performance. In an attempt to understand the kinetics of the system, we have calculated the rate of transport across the membrane. As flux is proportional to concentration on the donor side — which decreases with time - we performed a series of numerical simulations involving fixed time intervals of decreasing values. These calculations show that for the sizes of membranes in a typical FI system, transport is very slow compared with the adsorption of lead by the $\mathrm{Pb}-\mathrm{Spec}$ resin: it takes about $100 \mathrm{~min}$ for the concentration in a $0.06 \mathrm{~mL}$ donor solution to decrease by a factor of 1000 . The time required for the same decrease in concentration for a membrane having the same surface area and ligand concentration as the $\mathrm{Pb}-\mathrm{Spec}$ column was calculated as approximately $9 \mathrm{~s}$.
\end{abstract}

Key words: supported liquid membrane, solid-phase extraction, flow-injection, lead.

Résumé : Le transport sélectif d'un ion métallique cible à travers une membrane à partir d'un donneur vers une solution accepteuse est un concept attrayant pour la préconcentration ou la séparation dans un système à injection continue (IC). Cependant, nous avons trouvé que le transport du plomb à travers une membrane liquide incrustée dans un support, cette membrane est constituée de dicyclohexano-18-couronne-6 dans le décanol incorporé dans du Celgard 2400, est trop lent pour être pratique dans un système de spectrométrie atomique à injection continue (IC). Par ailleurs la même chimie en continu dans un réacteur en phase solide (une mini colonne contenant une résine $\mathrm{Pb}-\mathrm{Spec}$ ), a donné une performance satisfaisante. Dans une tentative pour comprendre la cinétique du système, nous avons calculé la vitesse de transport à travers la membrane. Comme le flux est proportionnel à la concentration du côté du donneur, laquelle diminue avec le temps, nous avons réalisé une série de simulations numériques impliquant des intervalles de temps fixes de valeurs décroissantes. Ces calculs montrent que, compte tenu des dimensions des membranes dans un système typique à injection continue, le transport est très lent comparativement à l'adsorption du plomb par la résine $\mathrm{Pb}-\mathrm{Spec}$; il faut environ 100 minutes pour que la concentration dans $0,06 \mathrm{~mL}$ d'une solution donneuse décroisse d'un facteur de 1000. Le temps requis pour la même diminution de concentration dans le cas d'une membrane ayant la même superficie et la même concentration de ligand dans une colonne de $\mathrm{Pb}$-Spec est selon les calculs approximativement de $9 \mathrm{~s}$.

Mots clés : membrane liquide supportée, extraction en phase solide, injection continue, plomb.

[Traduit par la Rédaction]

\section{Introduction}

Analytical method development often involves sample pretreatment so that a potentially interfering component of the sample matrix, which may be present in relatively high concentration compared with that of the analyte, is removed. Another common problem is that the analyte concentration is below the detection limit, and thus preconcentration is needed. For example, the determination of trace elements in forensic bullet samples by inductively coupled plasma mass spectrometry (ICP-MS) is inhibited by the presence of the lead matrix, which causes analyte signal suppression. The removal of this element prior to introduction to the instrument is therefore required. On the other hand, the determination of lead in drinking water by flame atomic absorption spectrometry (FAAS) requires preconcentration. Flow injection (FI) analysis is a versatile sample pretreatment technique that can be useful for the automated removal of a

Received 6 April 2002.

E.R. Yourd and J.F. Tyson. ${ }^{1}$ Department of Chemistry, University of Massachusetts, 710 N. Pleasant Street, Amherst, MA $01003-$ 9306, U.S.A.

${ }^{1}$ Corresponding author (e-mail address: tyson@chem.umass.edu). 
sample matrix or the preconcentration of a sample component (1-3). FI manifolds can be tailored to specific applications by incorporating the appropriate on-line components, such as a packed column for solid-phase extraction (SPE) or a membrane cell.

In developing a method for the analysis of bullets by ICPMS, we initially chose FI-SPE to remove the lead (4). Most of the previous work on the use of solid-phase reactors in FI systems for the separation of analytes from matrices has been based on a protocol whose primary goal is preconcentration. The analytes are retained from a relatively large volume of solution, while the unwanted matrix components are discarded to waste. Following removal of any unretained matrix materials from the reactor, the analytes are eluted in the direction opposite to that in which the species were loaded and are transported to the detector.

Several design features of such a reactor are desirable. There should be rapid transport from the bulk liquid in the interstices between the solid particles to the surface of the particles. The binding of the analytes to the particle surface should also be rapid, while the reverse reaction should be slow (i.e., the reaction between the analyte and the surfaceimmobilized reagent should have a high "equilibrium" or binding constant). The surface density of the binding sites should be such that the reactor has sufficient capacity to retain all of the analyte species. As is well known from HPLC theory, important factors include particle size, column dimensions, and flow rate; to get high efficiency (in the chromatographic sense of minimum band broadening) when using HPLC, the particle size should be small: $5 \mu \mathrm{m}$ or less. Even for the miniature columns that are typically used in FISPE applications, the back-pressure generated by using small particles is often sufficiently high that it is difficult to obtain useful flow rates from peristaltic pump delivery.

In the typical FI-SPE preconcentration procedure, such considerations are not of prime importance, as the first part of the experiment is performed under conditions such that the capacity factor is very large (the analyte is retained on the column). All that is necessary is that during the passage of any given solute through the column, there is a high probability that the species will interact with the reagent immobilized at the particle surface and will be retained. For the second part of the experiment, broadening processes are relevant, as the goal is to elute the retained analyte in as small a zone of fluid as possible. This maximizes the instrument response peak height and minimizes the time required for this portion of the experiment. Guidelines, based on these considerations, have been developed by Fang (2) and can be summarized as the optimum conditions for FI-SPE preconcentration for trace element determination by atomic spectrometry. These guidelines involve column volumes between 20 and $250 \mu \mathrm{L}$ with aspect ratios (5) of 10-15, containing particles of 150-200 $\mu \mathrm{m}$, and sample loading at 8$9 \mathrm{~mL} \mathrm{~min}^{-1}$. Elution flow rates depend on the detection mode, as the eluent is delivered directly to the spectrometer.

When FI-SPE is to be used for matrix removal by retention of the matrix and direct determination of the analytes, the guidelines described above no longer apply. Now there are two important considerations: $(a)$ there must be sufficient retention of the matrix element to reduce its concentration to below that which causes problems with the subsequent analyte determinations, and $(b)$ there should be minimum peak broadening of the unretained analytes. The first consideration means that the columns are significantly larger than those typically used for trace element preconcentration and, thus, may be capable of substantial peak broadening. In addition to the purely "chromatographic" features of the experiment, the flow rate is constrained to values at which the detector has suitable signal-to-noise ratio, and factors affecting the throughput have to be considered. Both of these considerations have implications for the sample volume injected, which, as always in flow injection experiments, cannot simultaneously maximize signal and minimize throughput. In addition, the elution characteristics of the system are still relevant, as the retained matrix component must be removed at frequent intervals by a suitable eluent.

It is clear, though, from basic HPLC theory that from the viewpoint of both retaining a matrix component and minimizing the broadening of non-retained components, the particle size should be decreased. A number of beneficial features would be realized by working with particle sizes of $10 \mu \mathrm{m}$ or less. For these values, not only is the peak broadening very much less than for larger particle sizes, but the broadening is also essentially independent of flow rate, and relatively high flow rates could be used to load samples rapidly. Unfortunately, there is a practical limitation related to the high back-pressure generated by columns of useful dimensions filled with particles of this size, which far exceeds the capabilities of the peristaltic pumps used for fluid handling in such experiments. Because of the additional costs and complexities associated with high-pressure pumping in multi-line manifolds, this option is not considered viable. As the performance of a method based on SPE is clearly limited, we considered other options.

While there are a number of such procedures that might be considered for implementation in an FI format, selective transport across a flat membrane is attractive. The procedure may be implemented in a device with minimum backpressure and thus, when fluid is delivered by peristaltic pump, could accept much higher fluid flows than can a packed bed solid-phase reactor. The device also allows the facile separation of phases associated with interaction between a liquid sample and an immobilized "reagent"; this is not realized when phase transfer into another mobile phase (either liquid or gas) forms the basis of the separation.

There are numerous recent reports of chemical separations by supported liquid membranes (SLM) (6-13). The pores of a microporous solid support are impregnated with a hydrophobic liquid, forming the membrane that separates the sample (donor) and receiver solutions. The analyte, if it is soluble in the membrane liquid, diffuses from the sample solution, through the membrane, and into the receiver solution. The mass-transport efficiency can be significantly enhanced when the membrane incorporates a carrier molecule that complexes with the analyte and facilitates its transit through the membrane to the receiver solution, where the complex dissociates. The carrier remains within the membrane.

The affinity of macrocyclic crown ethers for specific cations is well known (14-17). Those cations with ionic radii most closely matching the dimensions of the cavity of the macrocycle will be selectively complexed. Cations that are 
significantly smaller than the cavity will be too far from the lone pairs of the oxygen to form an appreciable bond, while larger cations will not fit inside the cavity. The selectivity of crown ethers can be used to separate certain cations from a mixture, both for preconcentration purposes and for matrix removal.

We have investigated the feasibility of using an SLM in the flat-sheet configuration with the goal of removing lead from a matrix, as part of the sample pretreatment in the analysis of high-lead materials such as bullets. The membrane was impregnated with the crown ether dicyclohexano-18crown-6 (DC18C6), which has a cavity size selective for lead $(9,17,18)$. The lead-containing solution was introduced to the donor compartment of the membrane cell, and the receiver side was monitored for the appearance of transported lead. The transport process was also modeled mathematically. The experimental results were compared with the behavior predicted on the basis of the calculations. The model was also applied to a rapid FI-SPE procedure (4) based on the almost identical extraction chemistry $\left(0.75 \mathrm{~mol} \mathrm{~L}{ }^{-1} \mathrm{di}-\right.$ tert-butyldicyclohexano-18-crown-6 in decanol immobilized on Amberchrom CG-71 (19)), to understand why this process is kinetically favorable to FI applications while the SLM procedure is not.

\section{Experimental}

\section{Reagents and standards}

Celgard 2400 polypropylene membranes (thickness $25 \mu \mathrm{m}$, porosity $35 \%$, pore sizes $0.041 \mu \mathrm{m} \times 0.12 \mu \mathrm{m}$; Celgard Inc., Charlotte, NC) and Pb-Spec (100-150 $\mu \mathrm{m}$ diameter, Eichrom, Inc., Darien, IL) were used as received. Dicyclohexano-18-crown-6, phenylhexane, and decanol (Sigma-Aldrich, Milwaukee, WI) were also used as received. Ten millilitre solutions of 0.05 and $0.10 \mathrm{~mol} \mathrm{~L}^{-1}$ crown ether in decanol and $0.05 \mathrm{~mol} \mathrm{~L}^{-1}$ crown ether in phenylhexane were prepared. A stock solution of $1000 \mathrm{mg} \mathrm{L}^{-1} \mathrm{~Pb}$ was prepared by dissolving the appropriate amount of lead nitrate (Certified ACS grade, Fisher Scientific) in 2\% (volume fraction) nitric acid (Mallinckrodt). Solutions of 50 and $250 \mu \mathrm{g} \mathrm{L}^{-1} \mathrm{~Pb}$ and $20 \mathrm{mg} \mathrm{L}^{-1} \mathrm{~Pb}$, all in $2 \% \mathrm{HNO}_{3}$, were prepared through the dilution of a $1000 \mathrm{mg} \mathrm{L}^{-1}$ atomic absorption standard (Sigma-Aldrich, Milwaukee, WI). Solutions of $3 \% \mathrm{HNO}_{3}$ and $0.1 \mathrm{~mol} \mathrm{~L}^{-1}$ ammonium citrate (Certified ACS grade, Fisher Scientific, $\mathrm{pH}$ 5.23) were prepared for use in the membrane cell. A dilute solution of alkaline phenolphthalein (Certified ACS grade, Fisher Scientific) was made by dissolving a sufficient amount of the indicator along with some sodium hydroxide (Mallinckrodt) in water to produce a strongly colored solution. All solutions were prepared using deionized water with a resistivity of $18.0 \mathrm{M} \Omega$ (E-Pure, Barnstead) and were stored in acid-washed polyethylene (Nalgene) bottles.

\section{Apparatus}

A flame atomic absorption spectrometer model 1100B (PerkinElmer, Shelton, CT, U.S.A.) with deuterium background correction was used. The instrument was operated with a lead hollow cathode lamp according to the manufacturer's recommended conditions. The $10 \mathrm{~cm}$ air-acetylene burner head position was optimized in three dimensions while aspirating a $20 \mathrm{mg} \mathrm{L}{ }^{-1}$ solution of $\mathrm{Pb}$ in $2 \% \mathrm{HNO}_{3}$. The position of the nebulizer capillary in the venturi throat was adjusted such that the nebulizer suction was zero. This positioning ensured that the flow rate of the solution reaching the nebulizer was controlled solely by the peristaltic pump of the flow injection manifold.

A graphite furnace atomic absorption spectrometer model 4100ZL (PerkinElmer, Shelton, CT, U.S.A.) with Zeeman background correction and a lead hollow cathode lamp was operated in accordance with the manufacturer's recommended conditions. An AS-71 autosampler transferred $20 \mu \mathrm{L}$ of solution to the furnace, and the standard program for lead without matrix modification was used. The autosampler probe was rinsed with deionized water between injections. Peak area was measured.

An Olympus $\mathrm{BH}-2$ transmission microscope was used to visually inspect the $\mathrm{Pb}-\mathrm{Spec}$ resin. The $40 \times$ objective was used with a $10 \times$ eyepiece for a total magnification of $400 \times$. A small amount of resin was placed on a glass slide and suspended in a few drops of water. A coverslip was placed over the beads to hold them in place.

The flow injection manifold consisted of one peristaltic pump (Ismatec), one 6-port rotary valve, and a membrane cell. The manifold is shown schematically in Fig. 1.

The cell was constructed from two nylon blocks $(8 \mathrm{~cm} \times$ $3 \mathrm{~cm} \times 2 \mathrm{~cm})$, each with a central groove $(4 \mathrm{~cm} \times 2 \mathrm{~mm} \times$ $0.2 \mathrm{~mm}$ for receiver, $0.75 \mathrm{~mm}$ for donor). The sample volume of $130 \mu \mathrm{L}$ was propelled through a $20 \mathrm{~cm}$ length of tubing into the top block of the cell with a flow rate of $1.3 \mathrm{~mL} \mathrm{~min}^{-1}$. The receiver solution was pumped in the opposite direction from the donor, creating a counter-current flow. The Celgard 2400 polymeric membrane was soaked in a solution of dicyclohexano-18-crown-6 and either decanol or phenylhexane for a minimum of $15 \mathrm{~min}$, then placed between the blocks, physically separating the two channels. The entire cell was clamped between two aluminum plates. The pump tubing was Tygon $1.52 \mathrm{~mm}$ i.d. three-stop tubing (blue-yellow); manifold components were connected via $0.8 \mathrm{~mm}$ i.d. PTFE tubing.

The SPE manifold, which provides the basis for the comparison, has been described previously (4). To summarize, a $130 \mu \mathrm{L}$ sample was injected into a nitric acid carrier that moved the sample through a glass column $(5 \mathrm{~cm} \times 4 \mathrm{~mm}$ i.d.) packed with $105 \mathrm{mg}$ of $\mathrm{Pb}-\mathrm{Spec}$ resin. The now leadfree sample passed directly into the ICP-mass spectrometer for the determination of the diagnostic elements in bullets: $\mathrm{Ag}, \mathrm{As}, \mathrm{Bi}, \mathrm{Cd}, \mathrm{Cu}, \mathrm{Sb}$, and $\mathrm{Sn}$. The resin was rinsed with $0.1 \mathrm{~mol} \mathrm{~L}^{-1}$ ammonium citrate after every third sample injection to remove the accumulated lead.

\section{Characterization of transport}

To determine when the injected sample solution completely filled the donor channel, the time required for the sample to travel from the injection valve to the membrane cell was measured. A basic solution of phenolphthalein was injected into a water carrier so that this transport time could be evaluated visually.

Different compositions of receiver solution were investigated. The acceptor stream was $3 \% \mathrm{HNO}_{3}$ or 0.1 mol L $\mathrm{L}^{-1}$ ammonium citrate. The amount of $\mathrm{Pb}$ transported to the re- 
Fig. 1. Flow injection manifold for the SLM experiment. The dashed line indicates the position of the membrane.

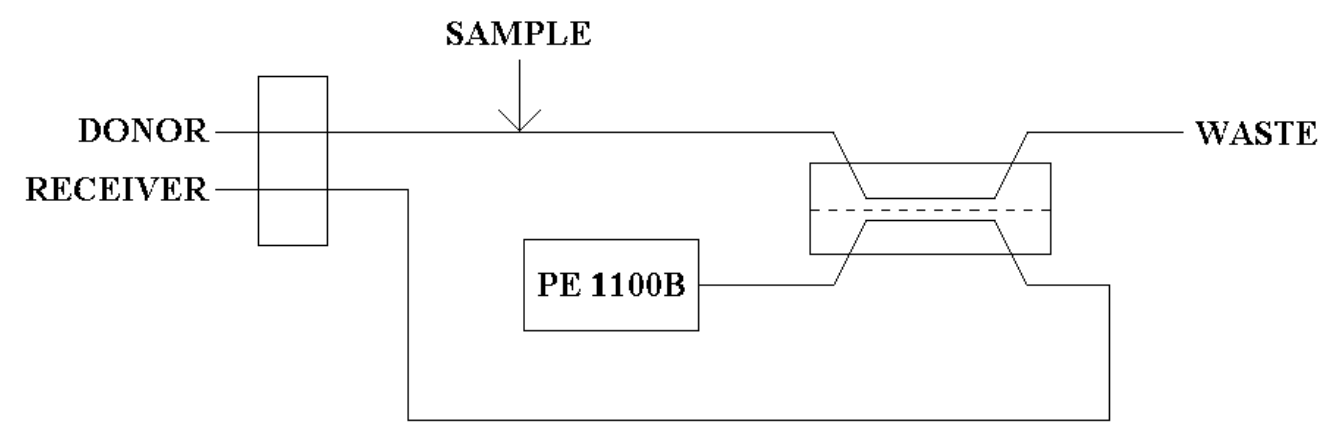

ceiver was observed for each solution after various stop times.

The contact time between the sample and the membrane was an important experimental parameter. The time required for lead to travel from the donor solution to the receiver was determined through a series of stopped-flow experiments with crown ether concentrations of 0.05 and $0.1 \mathrm{~mol} \mathrm{~L}^{-1}$ in decanol and $0.05 \mathrm{~mol} \mathrm{~L}^{-1}$ in phenylhexane. The $1000 \mathrm{mg} \mathrm{L}^{-1} \mathrm{~Pb}$ sample was injected into the $3 \% \mathrm{HNO}_{3}$ carrier stream and transported into the donor channel of the membrane cell. The pump controlling the two streams was stopped for a measured period of time $(0,5,15,30,60,120$, and $1320 \mathrm{~min}$ ) and then restarted. The absorbance due to lead in the ammonium citrate receiver solution was monitored by FAAS, and the height of the resulting lead peak was recorded.

The number of moles of lead transported across the SLM was quantified by electrothermal atomization atomic absorption spectrometry (ETAAS). The $1000 \mathrm{mg} \mathrm{L}^{-1} \mathrm{~Pb}$ sample solution was placed in contact with the SLM containing $0.1 \mathrm{~mol} \mathrm{~L}^{-1}$ DC18C6 in decanol for a stop time of $15 \mathrm{~min}$. At the end of the stop time, the receiver solution was pumped into a $25 \mathrm{~mL}$ volumetric flask and approximately $2 \mathrm{~mL}$ were collected. The solution was made to volume with $2 \% \mathrm{HNO}_{3}$. This sample was measured $(n=10)$ along with standards of 0,50 , and $250 \mu \mathrm{g} \mathrm{L}^{-1} \mathrm{~Pb}$ in $2 \% \mathrm{HNO}_{3}$. Each standard was measured five times.

\section{Mechanism of transport and calculations}

A theory of transport of divalent cations through a crownether-containing SLM has been developed (17, 20, 21). The cation flux is strongly dependent on the equilibrium constant $\left(K_{\mathrm{ex}}\right)$ for the following reaction $(20)$ :

[1] $\quad \mathrm{MA}_{m}{ }^{\mathrm{aq}}+\mathrm{L}^{\text {org }}=\mathrm{MA}_{m} \mathrm{~L}^{\text {org }}$

In this equation, $\mathrm{M}$ represents the metal cation, and $\mathrm{A}$ is a counterion present in the stoichiometric quantity $m$. L represents ligand. The superscripts in the equation refer to the aqueous (donor) and organic (membrane) phases. This reaction is the pertinent one, rather than the expected $\mathrm{M}^{m+}+\mathrm{nL}=$ $\mathrm{M}^{m+} \mathrm{L}_{n}$, because the transport of a cation by a neutral macrocycle requires the simultaneous transport of an anion to maintain electroneutrality. The transported moiety is therefore equivalent to $\mathrm{MA}_{m}$, a neutral species. Additionally, it is known that the rate-determining step in the mechanism is the diffusion of the complex through the membrane. A more accurate model would also account for the loss of macrocycle from the membrane, since carrier leaching would diminish the concentration of macrocycle available to move the cation.

The cation flux, $J$, can be calculated from a single equation containing terms whose values can either be measured or calculated readily (20):

$$
J=\frac{D K_{\mathrm{ex}}\left[\mathrm{L}_{\text {total }}{ }^{\mathrm{org}}\right]\left[\mathrm{MA}_{m}{ }^{\mathrm{aq}}\right]}{l\left(1+K_{\mathrm{ex}}\left[\mathrm{MA}_{m}{ }^{\mathrm{aq}}\right]\right)}
$$

The variables are defined as follows: $D$ is the diffusion coefficient of the neutral solute species, $\mathrm{MA}_{m} \mathrm{~L}^{\text {org }}$, through the membrane solvent; $\left[\mathrm{L}_{\text {total }}{ }^{\text {org }}\right]$ is the total concentration of crown ether in the organic solvent; $\left[\mathrm{MA}_{m}{ }^{\mathrm{aq}}\right]$ is the concentration of neutral solute species in the source phase; and $l$ is the membrane diffusion path length. The value of $D / l$ is generally calculated, because the $l$ value is difficult to obtain alone, owing to the need to include a term to account for membrane porosity and tortuosity. These values are calculated for each solvent-membrane system, so the value for Celgard 2400 with phenylhexane is used. The $K_{\mathrm{ex}}$ value can be measured experimentally, and the concentration of ligand is known from the membrane solutions. The units of $J$ are mol s${ }^{-1} \mathrm{~m}^{-2}$, incorporating time, area, and amount of substance.

This equation was used to predict the permeation behavior of $\mathrm{Pb}$ through a Celgard 2400 membrane soaked with DC18C6 in decanol or phenylhexane under stopped-flow conditions. The time required for the $\mathrm{Pb}$ concentration to change from 1000 to $1 \mathrm{mg} \mathrm{L}^{-1}$ in the donor solution was desired. This corresponded to the removal of a specific quantity of $\mathrm{Pb}$ matrix from a sample, which provided a value for the number of moles transported. The area of the SLM in contact with the donor in the flow injection experiments was calculated from measurements of the channel dimensions. These values, when combined with the calculated flux, allowed for the calculation of the transport time. To a first approximation, it was assumed that the behavior of the system with decanol was similar to that with phenylhexane, so the equilibrium constants and other variables for phenylhexane were used.

Before it is possible to calculate the flux of $\mathrm{Pb}$ across the membrane, however, the concentration of the neutral species available for transport must be obtained. The remaining variables in the flux equation are known: $D / l$ for the Celgard 2400-phenylhexane system $\left(3.19 \times 10^{-4} \mathrm{~L} \mathrm{~s}^{-1} \mathrm{~m}^{-2}\right)(20), K_{\mathrm{ex}}$ for the complexation of $\mathrm{Pb}\left(\mathrm{NO}_{3}\right)_{2}$ with DC18C6 (398.11) (20), and the concentration of DC18C6 in the membrane soaking solution. The only unknown, then, is the concentra- 
tion of $\mathrm{Pb}\left(\mathrm{NO}_{3}\right)_{2}$ in the donor. This value depends on the initial amount of $\mathrm{Pb}$ in the sample $\left(1000 \mathrm{mg} \mathrm{L}^{-1}\right)$ and the concentration of $\mathrm{HNO}_{3}$ (volume fraction 0.02).

To calculate the amount of $\mathrm{Pb}$ in the sample present as $\mathrm{Pb}\left(\mathrm{NO}_{3}\right)_{2}$, an iterative approach to the systematic treatment of equilibrium was taken. Using the $\beta$ (log stepwise formation constant) values (18) for the formation of $\mathrm{PbNO}_{3}{ }^{+}$and $\mathrm{Pb}\left(\mathrm{NO}_{3}\right)_{2}$ (2.14 and 2.15 , respectively) and the sample concentration of $1000 \mathrm{mg} \mathrm{L}^{-1}$ for the total amount of $\mathrm{Pb}$, it was possible to compute $\left[\mathrm{Pb}^{2+}\right]$ from the mass balance equation for lead. This value for $\left[\mathrm{Pb}^{2+}\right]$ was used, along with the appropriate $\beta$ value and the concentration of unbound $\mathrm{NO}_{3}{ }^{-}$in solution, to obtain the concentration of $\mathrm{Pb}\left(\mathrm{NO}_{3}\right)_{2}$. The total amount of nitrate anion bound up in all of the complexes was calculated and subtracted from the initial value. This adjusted initial value was used as the starting condition for the next iteration of the calculation, yielding a new $\left[\mathrm{Pb}\left(\mathrm{NO}_{3}\right)_{2}\right]$ and [unbound $\mathrm{NO}_{3}^{-}$]. This iterative process was performed five times, at which point the calculated concentrations of $\mathrm{Pb}\left(\mathrm{NO}_{3}\right)_{2}$ and $\mathrm{NO}_{3}^{-}$had each converged. The concentration of the neutral species was substituted into the flux equation, and the flux was calculated, yielding the quantity of $\mathrm{Pb}$ that could be transported.

The flux equation only describes an instantaneous condition. Immediately after the transport of $\mathrm{Pb}$ begins, the total concentration of $\mathrm{Pb}$ on the donor side decreases. This produces a new concentration for the neutral species and, hence, a different value for the flux. To account for this, the flux was assumed to be constant over a specific period of time, after which the concentration of $\mathrm{Pb}$ remaining in the donor solution was calculated and a new flux computed. The initial $\mathrm{Pb}$ concentration in the sample was $1000 \mathrm{mg} \mathrm{L}^{-1}$ and the desired final concentration was $1 \mathrm{mg} \mathrm{L}^{-1}$, which produced a defined end for the process. Time increments of 600,300 , 60,15 , and $1 \mathrm{~s}$ were used.

In earlier work (4) we devised an FI-SPE procedure based on $\mathrm{Pb}$-Spec $\left(0.75 \mathrm{~mol} \mathrm{~L}^{-1}\right.$ di-tert-butyldicyclohexano-18crown-6 in decanol immobilized on Amberchrom CG-71 (19)), which successfully removed the lead from digested bullet samples, allowing for accurate analyte determinations by ICP-MS. Although the overall analysis time was rather long for routine use, the rate of the lead removal was compatible with a flow rate of approximately $1 \mathrm{~mL} \min ^{-1}$. To compare the performance of a column of $\mathrm{Pb}$-Spec with that of the SLM, Pb-Spec was considered to consist of a thin coating of crown ether solution on the surfaces of impermeable spherical particles. Thus, each particle was imagined to function as a miniature, single-sided liquid membrane.

Physical characteristics of the $\mathrm{Pb}-\mathrm{Spec}$ resin were calculated from information provided by the manufacturer, Eichrom, Inc. The resin bead size ranged from 100 to $150 \mu \mathrm{m}$, so for spherical beads the surface area ranged from 0.0314 to $0.0707 \mathrm{~mm}^{2}$ per bead. Visual inspection through a transmission light microscope showed that the particles appeared uniformly spherical. It was therefore concluded that the surface area calculated on the basis of spherical resin beads was sufficient for use in subsequent calculations. From the dimensions of the resin bed $(2.3 \mathrm{~cm} \times 4 \mathrm{~mm}$ i.d. $)$ within the glass column, the volume of resin was $0.289 \mathrm{~mL}$. The resin has a free column volume of $0.65 \mathrm{~mL}$ per $\mathrm{mL}$ resin bed (19), or $0.188 \mathrm{~mL}$ in this specific column. Thus the volume occupied by the resin was $0.101 \mathrm{~mL}$. By considering the volume of spheres with diameters of 100 and $150 \mu \mathrm{m}$, the total number of beads in a volume of $0.101 \mathrm{~mL}$ was computed: $1.93 \times 10^{5}$ beads if they are all $100 \mu \mathrm{m}$ and $5.71 \times 10^{4}$ if $150 \mu \mathrm{m}$. Factoring in the surface area of an individual bead, the total surface area in a column containing $105 \mathrm{mg}$ of $100 \mu \mathrm{m}$ beads is $0.00605 \mathrm{~m}^{2}$ and $0.00403 \mathrm{~m}^{2}$ for a column of $150 \mu \mathrm{m}$ beads.

As the flux is calculated per unit area, the effect of membrane surface area is one of direct proportion. Different surface areas were considered. The contact area of the flat sheet membrane in the nylon cell, $8 \times 10^{-5} \mathrm{~m}^{2}$, was included, as well as the $\mathrm{Pb}$-Spec column areas of 0.00403 and $0.00605 \mathrm{~m}^{2}$.

The effect of crown ether concentration on rate of transport was examined. Values of $0.05 \mathrm{~mol} \mathrm{~L}^{-1}$ DC18C6 (SLM) and $0.75 \mathrm{~mol} \mathrm{~L}^{-1}(\mathrm{~Pb}-\mathrm{Spec})$ were substituted into eq. [2].

\section{Results and discussion}

\section{Experimental}

The membrane polymeric support consisted of a sheet of Celgard 2400 with approximate dimensions $4.5 \mathrm{~cm} \times$ $3.5 \mathrm{~cm}$. This effectively covered the faces of the membrane cell blocks. The white membrane, made from $25 \mu \mathrm{m}$ thick polypropylene, was hydrophobic and shed water as droplets. After the membrane was soaked in an organic solvent, however, it was completely wetted and became transparent. Because the membrane was then placed in contact with aqueous donor and receiver solutions, it was vital that the organic solvent be immiscible in water. A comparison (18) of water solubilities of common membrane solvents (chloroform: $7950 \mathrm{mg} \mathrm{L} \mathrm{L}^{-1}$; toluene: $526 \mathrm{mg} \mathrm{L} \mathrm{L}^{-1} ; 1,2-$ dichlorobenzene: $156 \mathrm{mg} \mathrm{L}^{-1}$; decanol (22): $3.70 \mathrm{mg} \mathrm{L}^{-1}$; phenylhexane: $0.902 \mathrm{mg} \mathrm{L}^{-1}$ ) indicates that phenylhexane is the solvent with the lowest water solubility, followed by decanol.

The time required for the phenolphthalein slug to arrive at the membrane cell and fill the donor channel was $12 \mathrm{~s}$. The dye experiment revealed that the $130 \mu \mathrm{L}$ sample slug underwent noticeable dispersion, allowing only a relatively small portion of the sample volume to be in contact with the membrane during the stop time.

The better receiver solution was $0.1 \mathrm{~mol} \mathrm{~L}^{-1}$ ammonium citrate. This result, displayed in Fig. 2, was anticipated. The transport of $\mathrm{Pb}$ through the membrane was expected to be enhanced when the $\mathrm{Pb}$ was actively stripped from the membrane. The acid receiver was more passive, allowing the $\mathrm{Pb}$ to diffuse into it from the membrane. The ammonium citrate solution, however, allowed for the formation of a strong lead citrate complex, which provided an additional driving force for the $\mathrm{Pb}$ transport.

Figure 3 shows the results for the stopped-flow experiments using the two crown ether concentrations. The concentration of lead in the receiver solution increased with time until a constant value was obtained, which indicated that an equilibrium was reached. That is, the rates of transport of lead across the membrane in each direction were then equal. The results indicate that the membrane that contained $0.05 \mathrm{~mol} \mathrm{~L}^{-1}$ DC18C6 allowed more permeation of $\mathrm{Pb}$ than the other membranes. These findings contradict the results 
Fig. 2. The effect of different receiver solutions on $\mathrm{Pb}$ transport.

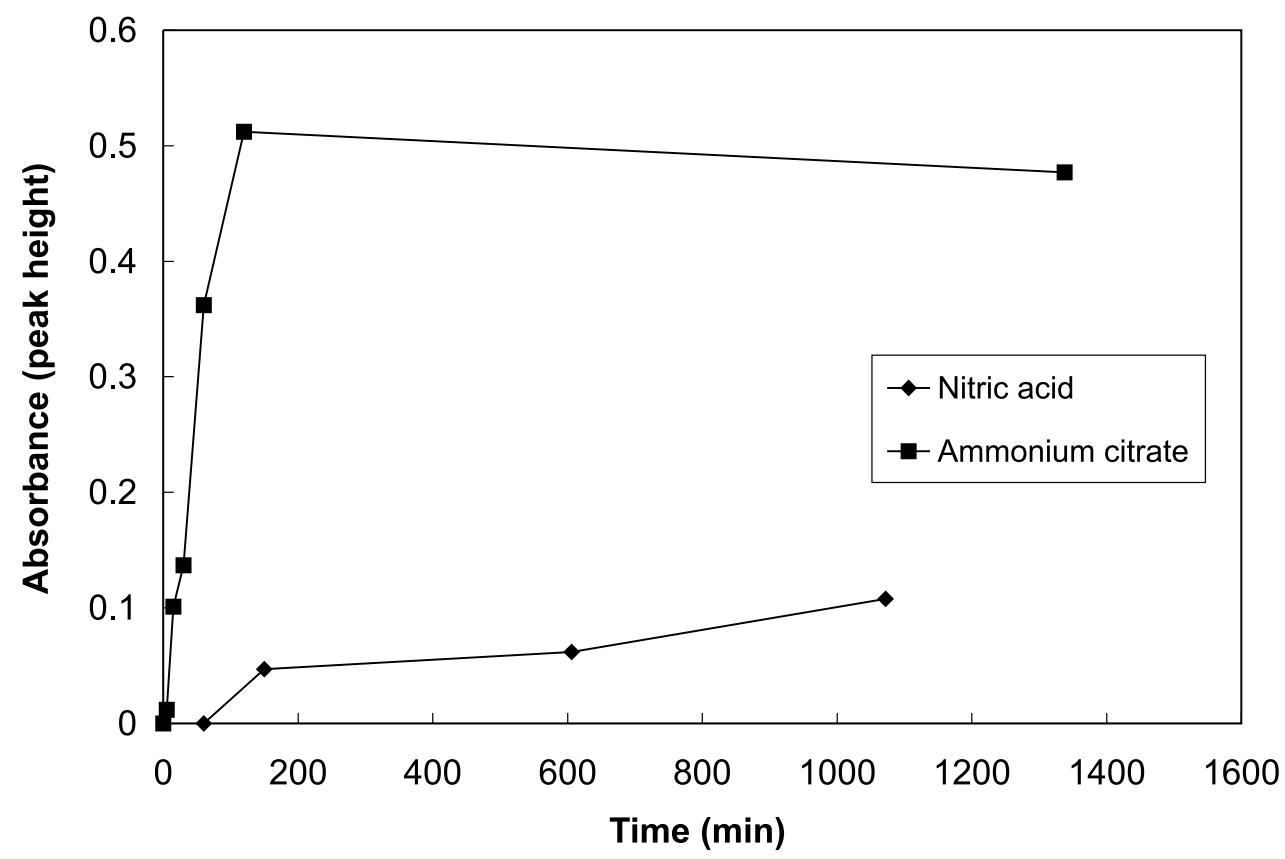

Fig. 3. Results for stopped-flow experiments. Each point represents a single measurement.

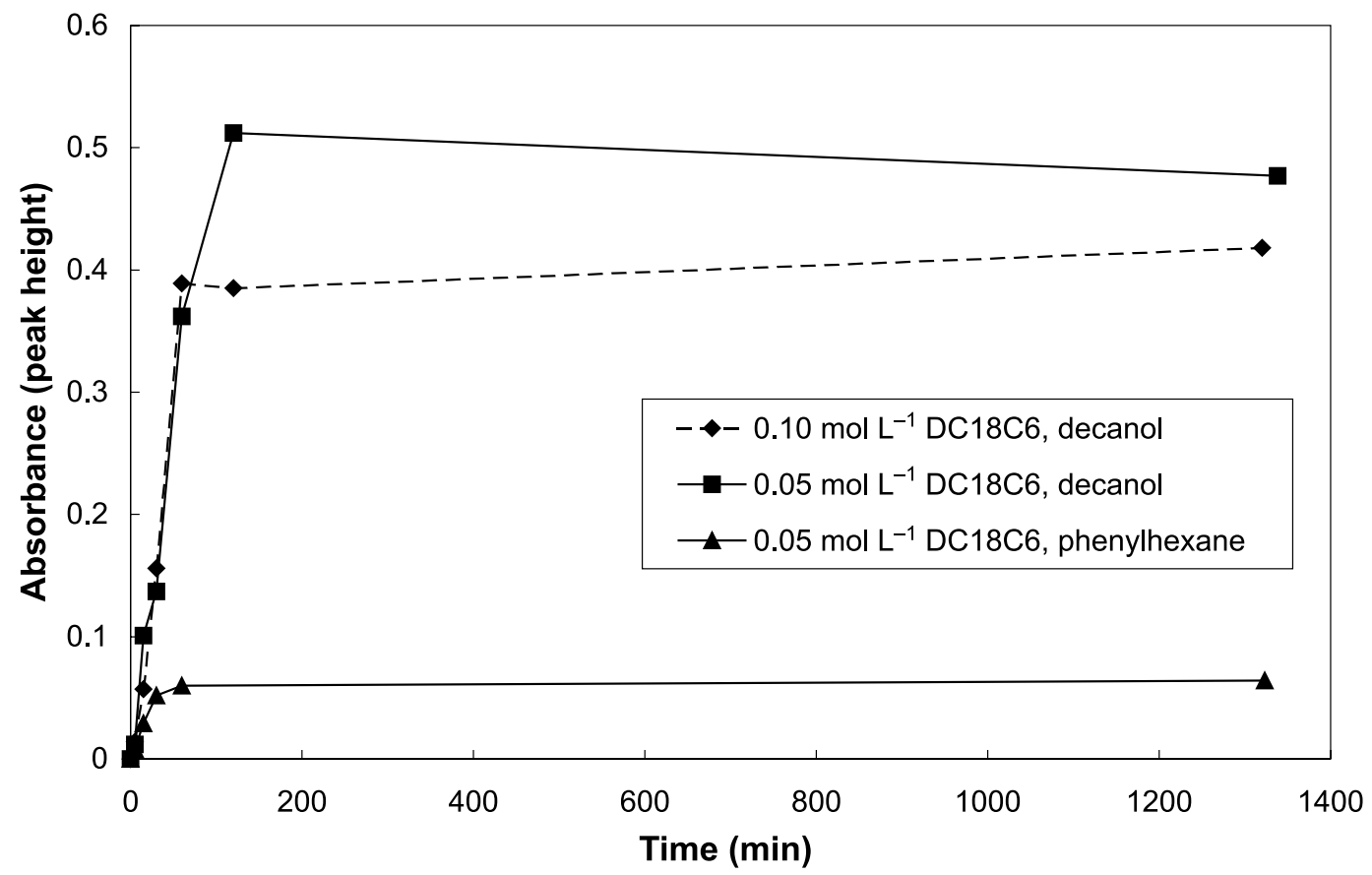

expected on the basis of eq. [2], from which it would be expected that the presence of more carrier molecules in the membrane would cause more $\mathrm{Pb}$ to be transferred. However, the higher concentration of crown ether may decrease the diffusion coefficient term in the numerator of eq. [2], which could account for the slower-than-expected rate of transport. Further investigation of this possibility was considered beyond the scope of the present study.

The $\mathrm{Pb}$ content of the $15 \mathrm{~min}$ stop flow point $\left(0.1 \mathrm{~mol} \mathrm{~L} \mathrm{~L}^{-1}\right.$ DC18C6 membrane) was measured off-line by ETAAS. The least-squares calibration equation produced by three standard solutions was $y=0.0016 x-0.0058$, where $y$ is the absorbance and $x$ the $\mathrm{Pb}$ concentration in $\mu \mathrm{g} \mathrm{\textrm {L } ^ { - 1 }}$. The correlation coefficient $r$ was 0.9996 . The concentration of $\mathrm{Pb}$ in the sample was $89.4 \mu \mathrm{g} \mathrm{L}^{-1}$, corresponding to $1.1 \times$ $10^{-8}$ moles $\mathrm{Pb}$ in the $25 \mathrm{~mL}$ flask. This amount of $\mathrm{Pb}$ was transported across the membrane in 15 min. Assuming a linear relation between absorbance and concentration, the FAAS absorbances for each of the other stop times were calculated from this point, as shown in Fig. 4. The $0.05 \mathrm{~mol} \mathrm{~L}^{-1}$ 
Fig. 4. The number of moles transported across the membrane at each stopped-flow time. The 15 min point for the 0.1 mol $\mathrm{L}^{-1}$ DC18C6 membrane was quantified by ETAAS, from which all other $y$-values are calculated.

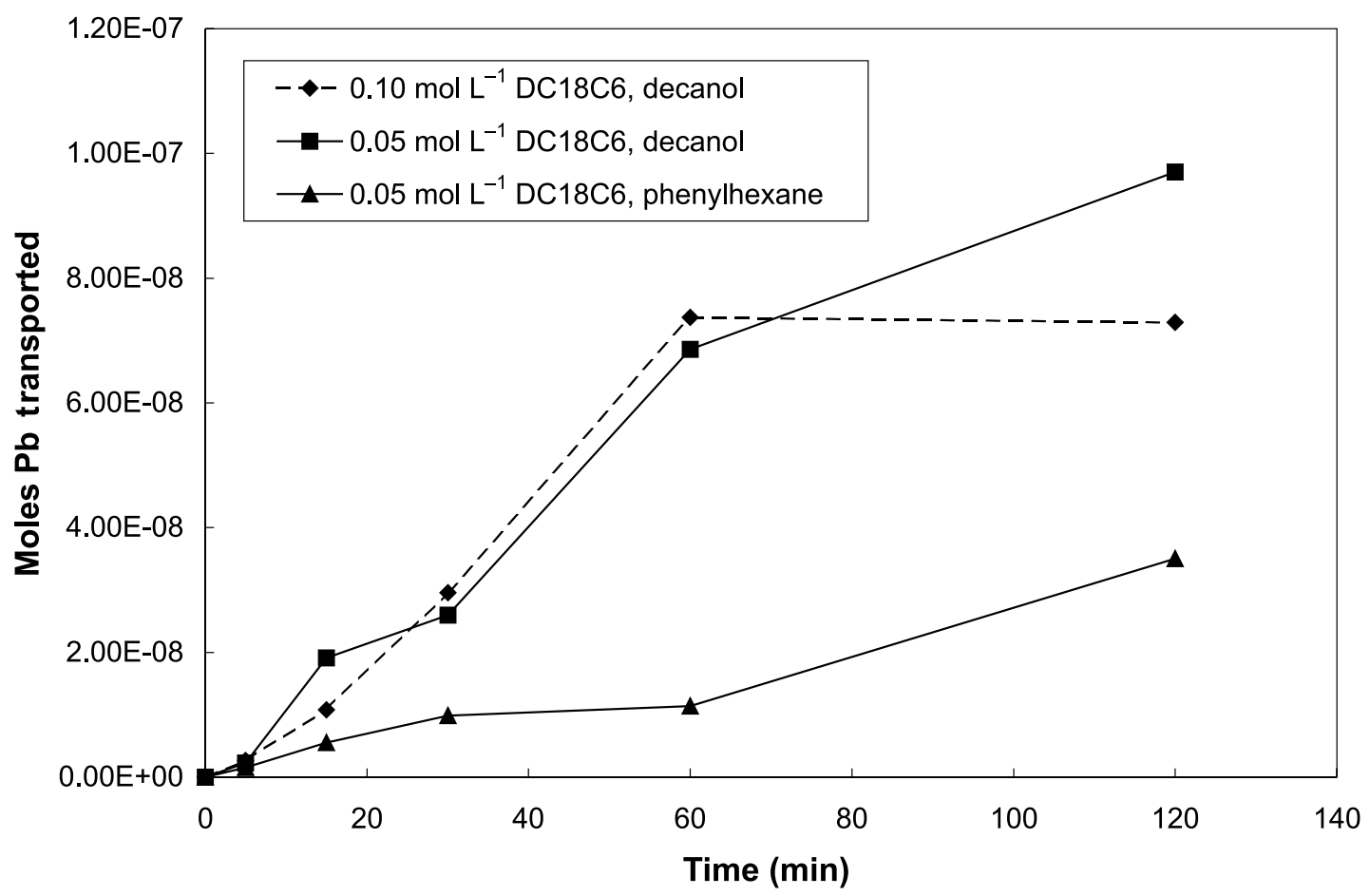

DC18C6 membrane absorbances were also calculated from this value.

It is clear from Figs. 3 and 4 that the kinetics of transport for the flat sheet SLM are too slow for the process to be implemented in a flow injection mode. The transfer mechanism relies on the diffusion of the $\mathrm{Pb}$ - crown ether complex through the membrane, for which the concentration gradient of $\mathrm{Pb}$ is a driving force. Thus, if the receiver solution is not stagnant, this diffusion would continue, and eventually the desired amount of lead could be transported across the membrane. However, in this mode of operation, the transport processes would not produce any preconcentration.

The $\mathrm{Pb}$ transport rate is also proportional to the membrane area. As the dispersion of the sample slug allowed only a small portion of the initial volume to be in contact with the membrane during the stop time, the rate of transport was less than would be obtained with either a larger surface area or a smaller sample volume. Although, the additional dispersion incurred with a smaller sample volume would probably offset this benefit, owing to the decreased concentration in the donor phase.

\section{Model calculations}

The calculated number of moles of $\mathrm{Pb}$ remaining in the donor solution is plotted as a function of the elapsed time in Fig. 5. As the time increments decreased, the system was described more accurately, since chemical processes are rapid. Also, the new plots became more and more similar until they converged. It was therefore assumed that further reducing the increments would not substantially alter the predicted transport time.

The line for the calculations using $5 \mathrm{~s}$ increments overlapped that for the $1 \mathrm{~min}$ increments so that they are indis- tinguishable on the figure. Both lines showed a total transport time of $105 \mathrm{~min}$; the $5 \mathrm{~s}$ trace was subsequently omitted from the plot for clarity.

In addition to calculating the number of moles of $\mathrm{Pb}$ remaining in the donor solution vs. elapsed time, the number of moles appearing in the receiver could be derived. A comparison between the calculated transport and the experimental values for the two membranes containing $0.05 \mathrm{~mol} \mathrm{~L}^{-1}$ crown ether may be made from the plots in Fig. 6. One reason for the low experimental rate compared with the calculated rate may be the leaching of macrocycle from the membrane. Izatt et al. (20) calculated that for a similar crown ether and phenylhexane in Celgard 2400, about $90 \%$ of the macrocycle was lost. It should be noted, however, that their calculations modeled transport under conditions in which both the donor and acceptor solutions were constantly stirred.

When the total surface area of the $\mathrm{Pb}-\mathrm{Spec}$ resin was inserted into the flux equation, the time for the lead concentration to reach $1 \mathrm{mg} \mathrm{L}^{-1}$ was significantly diminished for a membrane containing $0.05 \mathrm{~mol} \mathrm{~L}^{-1}$ ligand. For an area of $0.00605 \mathrm{~m}^{2}(100 \mu \mathrm{m}$ resin $)$, the transport time is $2.5 \mathrm{~min}$ for $10 \mathrm{~s}$ increments. The time is $4.1 \mathrm{~min}$ when the area is $0.00403 \mathrm{~m}^{2}$ (150 $\mu \mathrm{m}$ resin) for the same increments.

Increasing the ligand concentration in the SLM had a significant effect on the transport time. With $0.75 \mathrm{~mol} \mathrm{\textrm {L } ^ { - 1 }}$ ligand and the membrane area held at the experimental value of $8 \times 10^{-5} \mathrm{~m}^{2}$, the time was $6.7 \mathrm{~min}$ with $10 \mathrm{~s}$ increments of constant flux. When the area of the $100 \mu \mathrm{m}$ resin is combined with the increased ligand concentration, the transfer time calculated from $1 \mathrm{~s}$ increments is diminished to $8.7 \mathrm{~s}$. The value obtained for the $150 \mu \mathrm{m}$ resin corresponds to $15.3 \mathrm{~s}$. 
Fig. 5. Calculated number of moles remaining in the sample as a function of time for different time increments used in the flux calculations. Inset is an enlargement of the region where the calculated concentrations go below $1 \mathrm{mg} \mathrm{L}^{-1} \mathrm{~Pb}$.

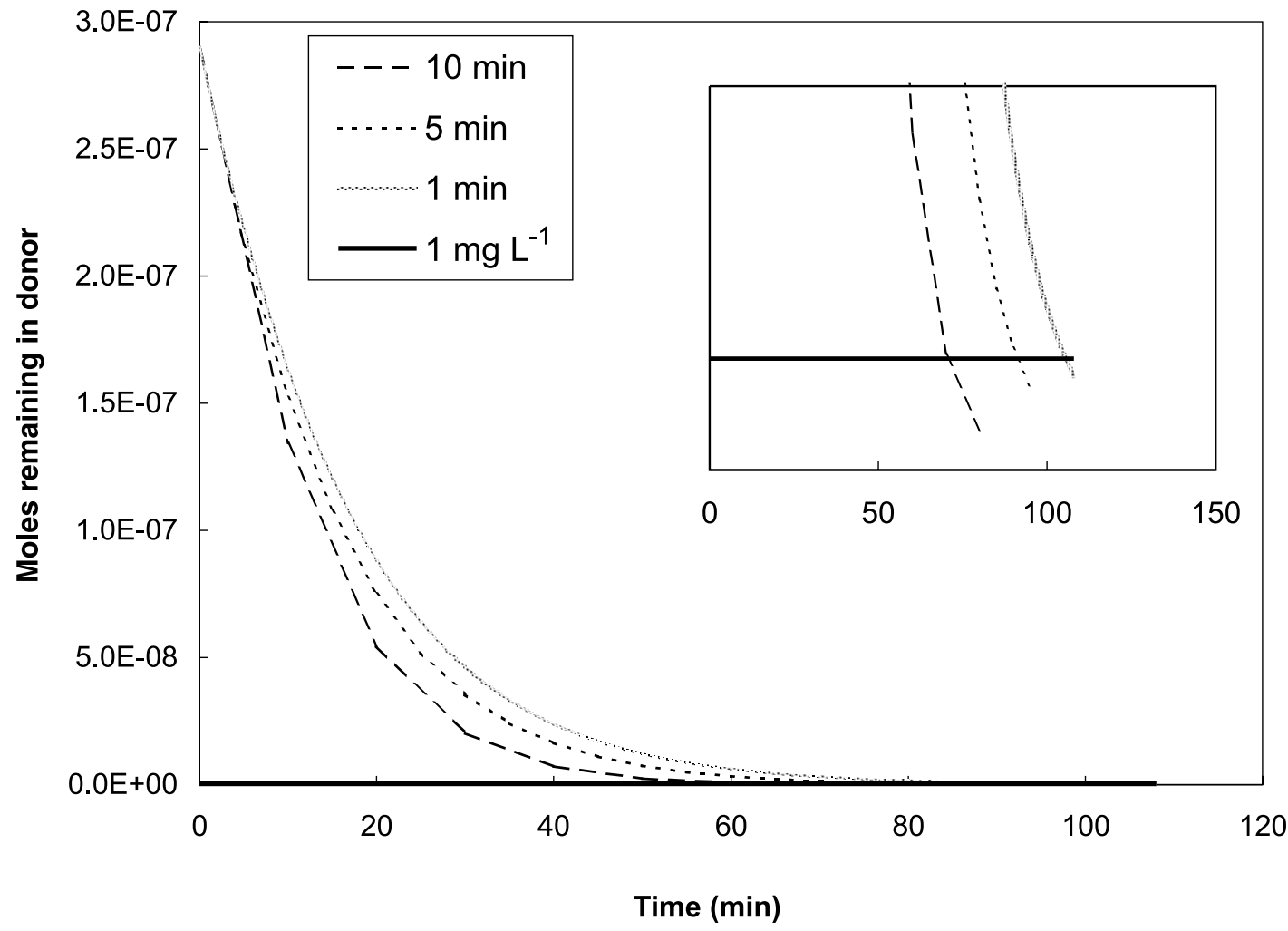

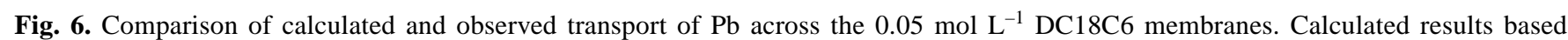
on $1 \mathrm{~min}$ increments.

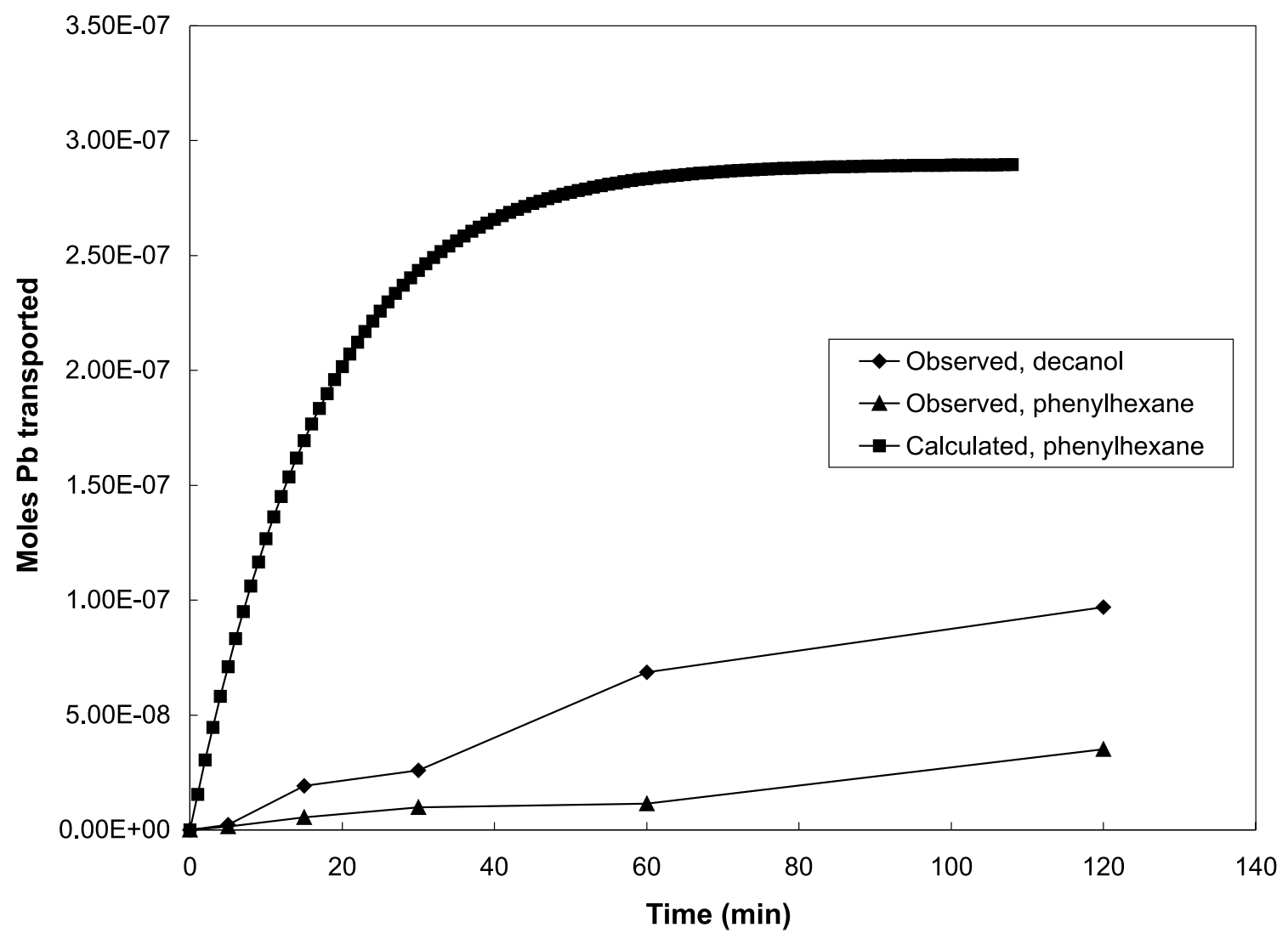


As can be seen from Figs. 3, 4, and 6, decanol is to be preferred over phenylhexane as an SLM solvent, though the reasons for this are not immediately obvious. Decanol has higher viscosity and water solubility than phenylhexane, though information regarding the diffusion coefficients of DC18C6 in these solvents is not immediately available. However, the results confirm that decanol is an appropriate choice for the formulation of the Pb-Spec SPE material.

\section{Conclusions}

Separations by SLM systems are not feasible for on-line, dynamic, flow injection applications. Although the advantages of SLMs (i.e., the lack of back-pressure and sample dispersion, as well as the single-step analysis procedure) make these devices attractive for this type of analysis, both experimental results and model calculations indicate that the transport processes are too slow for typical FI systems. On the other hand, the same chemistry conducted in thin films coated on spherical beads is compatible with FI time scales. It is concluded that this is due largely to the increased surface area of the "membrane". This raises the question, to what extent could the SLM performance be improved by using a bundle of hollow fibers instead of a flat sheet? For example, a bundle of 140 Celgard X-30 240 fibers (i.d. $240 \mu \mathrm{m}$, o.d. $300 \mu \mathrm{m}$ ) packed into a $5 \mathrm{~cm}$ column has a total internal surface area of approximately $0.0045 \mathrm{~m}^{2}$. This value is comparable to that obtained for the $100 \mu \mathrm{m} \mathrm{Pb}-\mathrm{Spec}$ beads, implying that such a bundle might have a feasible rate of transport for use in a flow injection manifold.

\section{Acknowledgements}

Financial support for E.Y. from The Schering-Plough Research Institute is gratefully acknowledged. We also thank Celgard, Inc. for the gift of Celgard 2400 and Eichrom, Inc., for the donation of $\mathrm{Pb}$-Spec. This material is based on work supported by the National Science Foundation under grant No. 0094568.

\section{References}

1. Z. Fang. Flow injection atomic absorption spectrometry. John Wiley \& Sons, New York. 1995.
2. Z.-L. Fang. Flow injection separation and preconcentration. VCH Publishers, Inc., New York. 1993.

3. A. Sanz-Medel (Editor). Flow analysis with atomic spectrometric detectors. Elsevier Science, Amsterdam. 1999.

4. E.R. Yourd, J.F. Tyson, and R.D. Koons. Spectrochim. Acta B, 56, 1731 (2001).

5. M.A. Marshall and H.A. Mottola. Anal. Chem. 57, 729 (1985).

6. J. de Gyves and E.R. de San Miguel. Ind. Eng. Chem. Res. 38, 2182 (1999).

7. J.A. Jonsson and L. Mathiasson. Trends Anal. Chem. 18, 325 (1999).

8. K.K. Sirkar, P.V. Shanbhag, and A.S. Kovvali. Ind. Eng. Chem. Res. 38, 3715 (1999).

9. J.D. Lamb, R.M. Izatt, D.G. Garrick, J.S. Bradshaw, and J.J. Christensen. J. Membr. Sci. 9, 83 (1981).

10. N. Parthasarathy and J. Buffle. Anal. Chim. Acta, 284, 649 (1994).

11. A. El-Bachiri, A. Hagege, and M. Burgard. J. Membr. Sci. 121, 159 (1996).

12. M. Akhond and M. Shamsipur. Sep. Sci. Technol. 32, 1223 (1997).

13. N.K. Djane, K. Ndungu, F. Malcus, G. Johansson, and L. Mathiasson. Fresenius J. Anal. Chem. 358, 822 (1997).

14. J.D. Lamb and M.D. Christenson. J. Incl. Phenom. Mol. Recogn. Chem. 32, 107 (1998).

15. J.S. Bradshaw and R.M. Izatt. Acc. Chem. Res. 30, 338 (1997)

16. J.D. Lamb, R.M. Izatt, P.A. Robertson, and J.J. Christensen. J. Am. Chem. Soc. 102, 2452 (1980).

17. S. Dernini, A. Scrugli, S. Palmas, and A.M. Polcaro. J. Chem. Eng. Data 41, 1388 (1996).

18. J.D. Lamb, R.L. Bruening, R.M. Izatt, Y. Hirashima, P.K. Tse, and J.J. Christensen. J. Membr. Sci. 37, 13 (1988).

19. E.P. Horwitz, M.L. Dietz, S. Rhoads, C. Felinto, N.H. Gale, and J. Houghton. Anal. Chim. Acta, 292, 263 (1994).

20. R.M. Izatt, R.L. Bruening, M.L. Bruening, G.C. Lindh, and J.J. Christensen. Anal. Chem. 61, 1140 (1989).

21. G. Audunsson. Anal. Chem. 58, 2714 (1986).

22. P.H. Howard and W.M. Meylan (Editors). Handbook of physical properties of organic chemicals. CRC Press, Inc., Boca Raton, Fla, U.S.A. 1997. 